\title{
PROJEKT FACES (FREELY ACCESSIBLE CENTRAL EUROPEAN SOIL) - TERENSKI SESTANEK V SLOVENIJI, MAJ 2017
}

$\mathrm{V}$ zadnjih letih se je na evropski in svetovni ravni raziskovanje in proučevanje prsti izjemno razmahnilo ter razširilo. Posledično je to na državnih ravneh prineslo veliko raznolikost in raznovrstnost metod, podatkovnih baz, klasifikacij in poimenovanj. Zato je komuniciranje, izmenjava mnenj in čezmejno sodelovanje med strokovnjaki, pedagogi in študenti različnih držav precej oteženo. Ta hip na nivoju Evropske unije ni predpisane in poenotene metodologije znanstvenega raziskovanja in poučevanja s področja proučevanja prsti. Zato se je pod njenim okriljem v okviru programa Erasmus+ razvil projekt Freely Accessible Central European Soil (FACES) z namenom kreiranja podatkovne baze prsti za del Evrope, ki pokriva Poljsko, Češko, Slovaško, Madžarsko, Slovenijo, Litvo, Latvijo in Estonijo. Glavni namen projekta je vzpostavitev mednarodne digitalne platforme in podatkovne baze za izmenjavo informacij o klasifikaciji prsti predvsem za potrebe poučevanja in izobraževanja. Pomembna značilnost podatkovne baze bo poenotena in med omenjenimi državami dogovorjena zasnova in oblika, ki temelji na mednarodni FAO WRB (World Reference Base for Soil Resources) klasifikaciji. Za cilje si je projekt zadal:

- Priprava priročnika/učbenika za opis profilov prsti, ki bi bil namenjen izobraževalnim potrebam.

- Vzpostavitev enotne zbirke podatkov o prsteh Srednje Evrope, ki temeljijo na klasifikaciji WRB (različica 2015).

- Izdelava spletnih prikazov, 3D sferičnih panoramskih posnetkov profilov prsti in okoliške pokrajine, ki bodo služili kot didaktično orodje za univerze po Evropi.

- Izdaja serije atlasov in albumov prsti.

- Proučevanje uporabnosti tretje izdaje WRB klasifikacije prsti na območju partnerskih držav.

- Vrednotenje sistema WRB klasifikacije s poudarkom na različnih naravnih dejavnikih partnerskih držav.

- Priprava univerzitetnega učnega načrta, posvečenega poučevanju na podlagi tretje izdaje WRB klasifikacije prsti (2014/15).

- Vrednotenje izdelanega poskusnega modela poučevanja na podlagi študentskih delavnic.

Izpolnitev ciljev temelji na terenskih sestankih v državah partnericah, kjer na podlagi izkopanih profilov prsti in geografskega proučevanja okoliške pokrajine preverjamo uporabnost zasnovanih idej. Do sedaj je bilo izpeljanih 7 takšnih srečanj. Prvo je bilo oktobra 2015 v severni Poljski. Leta 2016 so bila tri: aprila v Slovaški, junija v Latviji in Estoniji ter septembra v južni Poljski in Češki. Tudi leta 2017 so bila tri: maja v Sloveniji, junija v Litvi (delavnica s študenti) in oktobra na Madžarskem. Zadnje bo julija 2018 ponovno na Poljskem kot delavnica s študenti. 
Projekt je prišel v svojo sklepno fazo, saj je razpisan za obdobje 2015-2018. Vodilna inštitucija je poljska Univerza Nikolaja Kopernika iz Toruńa. Ostale partnerske institucije so še: Univerza za okoljske in bio znanosti v Wroclawu (Poljska), Agronomska univerza v Jelgavi (Latvija), Univerza bio znanosti v Tartuju (Estonija), Pedološki in okoljski raziskovalni inštitut v Bratislavi (Slovaška), Univerza Aleksandra Stulginskisa v Kaunasu (Litva), Univerza v Debrecenu (Madžarska), Univerza v Ljubljani (Slovenija), Agronomska univerza v Pragi (Češka).

Spletna stran projekta je: https://sites.google.com/site/centraleuropesoils/home.

Na pomlad lanskega leta smo v Sloveniji gostili pomembne pedologe in geografe iz omenjenih držav. Rdeča nit terenskega sestanka so bili vinogradi in vinogradniške prsti. Zbrali smo se 8. 5. 2017 v Ljubljani. Nato smo se naslednjega dne odpeljali proti Beli krajini, kjer smo dali poudarek izpranim in vinogradniškim prstem. V dežju smo na karbonatni matični podlagi v dveh vinogradih v Kotu pri Semiču izkopali dve profilni jami. V prvem primeru smo prepoznali tipično izprano prst na antropogeni terasi z glinastimi prevlekami, pretežno ilovnato teksturo in kislim, bledim površinskim horizontom. Prst smo poimenovali Haplic Luvisol (Cutanic, Escalic, Loamic, Ochric), slika a. V drugem primeru je bila prst podobna, le da je nastala na blagem pobočju in z obilico skeletnih delcev pod površjem. Šlo je za Endoskeletic Luvisol (Cutanic, Loamic, Ochric), slika b. Zaradi izjemno slabega vremena smo izpustili prsti steljnikov. Pot smo nadaljevali pod Pohorje, v Tinjsko goro. Tudi tam smo v vinogradu izkopali dve profilni jami. Obe jami sta bili izkopani na pobočju, na mešani silikatni matični podlagi. $\mathrm{V}$ tem primeru je šlo prav tako za dva profila izpranih prsti, kjer so se pod površjem zaradi nepropustne matične podlage pojavljaje redukcijske razmere (psevdooglejevanje): Endoskeletic Luvisol (Cutanic, Loamic, Ochric), slika c in Endostagnic Luvisol (Cutanic, Ochric, Pantoloamic, Novic, Cambic), slika d. Prijazni domačini so udeležence seznanili s štajerskimi dobrotami, nato pa smo se odpravili proti Poljčanam. Ob Dravinji smo neposredno ob bregu prepoznali bazično, peščeno obrečno prst, Eutric Orthofluvic Fluvisol (Arenic, Ochric, Technic), slika e. Na aluvialni ravnici pa kislo, skeletno ilovnato kambično prst Dystric, Skeletic, Stagnic, Endoleptic Cambisol (Loamic, Ochric), slika f. Tipične psevdooglejene prsti Dravinjskih goric smo spoznali v Dolah pri Modražah. Tam smo odkrili debelo izprano prst, ki je nastala na koluvialnem, pretežno meljastem gradivu z globokim izpiranjem bazičnih kationov in redukcijskimi razmerami. Poimenovali smo jo Endocalcic Endostagnic Luvisol (Colluvic, Cutanic, Ochric, Episiltic, Endoloamic), slika g. Proučevanje nas je nato vodilo na Kras. Udeleženci so najprej spoznali lepote kraškega podzemlja Škocjanskih jam, nato pa smo se tudi tukaj posvetili vinogradom. Veliko dela smo imeli v Kregolišču. V prvem primeru smo izkopali profilno jamo v opuščeni delani vrtači, kjer je bila prst izjemno skeletna, Eutric Skeletic Chromic Cambisol (Loamic, Ochric), slika h. V vinogradu pa je bila jerovica zelo globoka. Šlo je za antropogeno preneseno, rdeče, kambično gradivo, ki je prekrivalo bivšo, izvorno rendzino: Eutric Rhodic Cambisol (Aric, Loamic, Ochric, Anotransportic) preko Mollic Leptosol, slika i. V vinogradu pri Komnu smo ugotavljali razlike med razmerami na različnih legah na pobočju (sredina in vznožje). V obeh primerih so bile prsti kambične (jerovice), evtrične, skeletno ilovnate, intenzivno oranžno obarvane, z bledim, kislim površinskim horizontom: Eutric Skeletic 
Chromic Leptic Cambisol (Loamic, Ochric), slika j in Eutric Skeletic Chromic Cambisol (Colluvic, Loamic, Ochric), slika k. Zadnji dan smo preživeli na obali in njenem zaledju. $\mathrm{Na}$ školjčišču pri Ankaranu smo imeli priliko videti za Slovenijo zelo redke zaslanjene prsti. Neposredno na obali je bila prst praktično povsem zalita z morsko vodo in polna školjk, Fluvic Gleyic Solonchak (Clayic, Calcaric), slika 1. Tudi nekaj 10 m stran, je bil vpliv morske vode še vedno izrazit, a ta ni več segala do površja (oglejevanje), Calcaric Gleysol (Amphigleyic, Ochric, Salic, Skeletic, Epiloamic), slika m. Zadnje mesto proučevanja je bilo v Koprskih brdih, na flišu, prav tako v vinogradu. Ne glede na to, da smo si ponovno izbrali dve različni legi na pobočju (zgornji in spodnji del pobočja), je šlo v obeh primerih za evtrične rjave prsti na flišu, kjer so se karbonati in skelet pojavljali po celotnem profilu, s psevdooglejevanjem pod površjem in ilovnato teksturo: Pantocalcaric Skeletic Endostagnic Cambisol (Loamic, Ochric), sliki n in o. Po spoznavanju dobrot primorske regije smo s terenskim sestankom zaključili in se odpravili nazaj proti Ljubljani.

Vsi udeleženci so bili nad obiskom Slovenije navdušeni. Vsekakor so bili pod vtisom lepot naše države, a so tudi s pedološkega vidika spoznali nove prsti. Šlo je predvsem za tipične prsti (ob)sredozemskih pokrajin ter izjemno pestrost vinogradniških prsti, ki jih v takšni obliki v državah Srednje in Vzhodne Evrope ni mogoče najti.

Profili prsti, izkopani in prepoznani na terenskem sestanku v Sloveniji v okviru projekta FACES (foto: B. Repe).

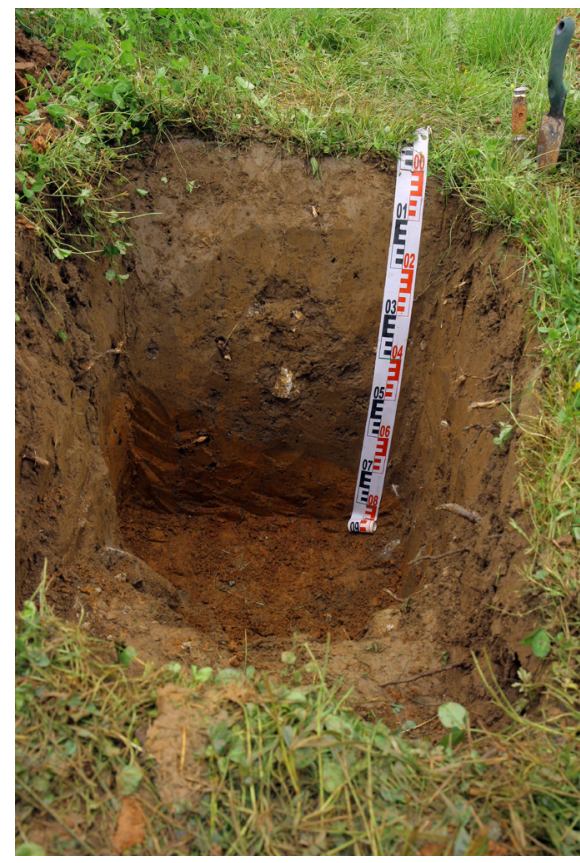

a

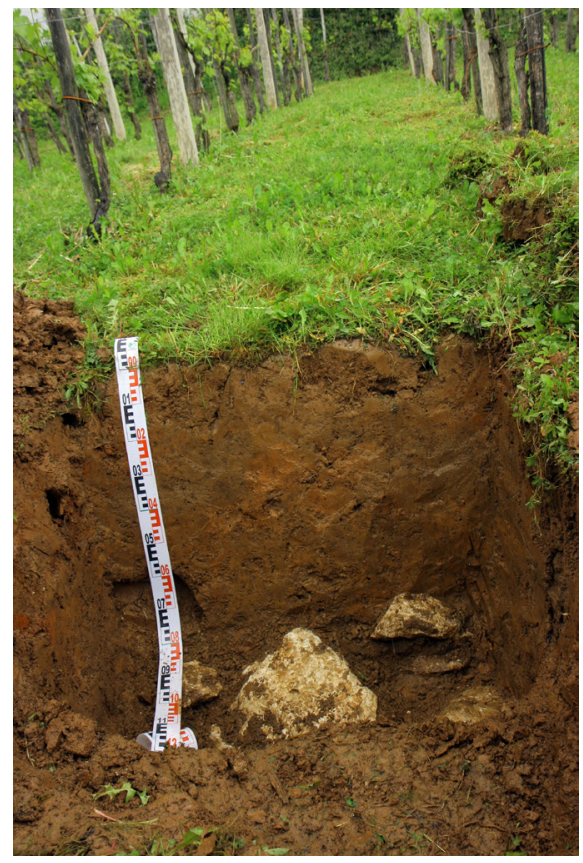

b 


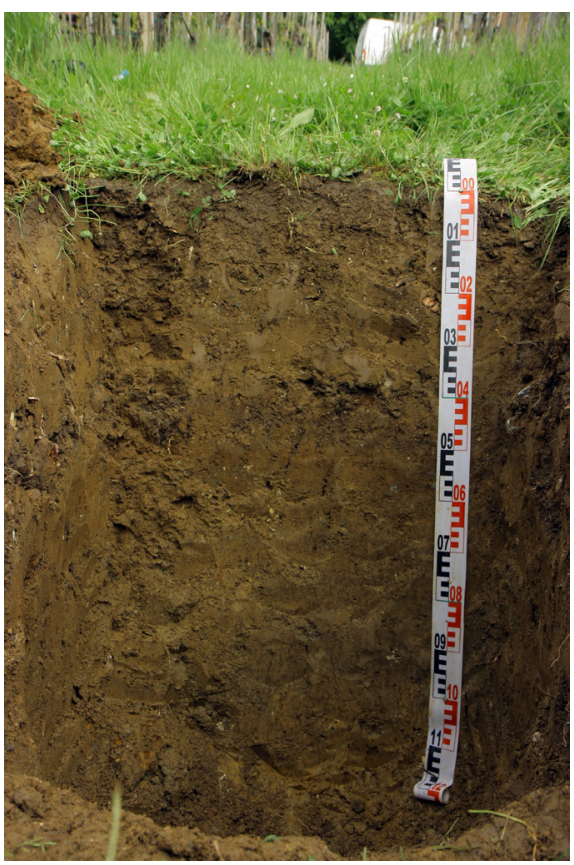

c

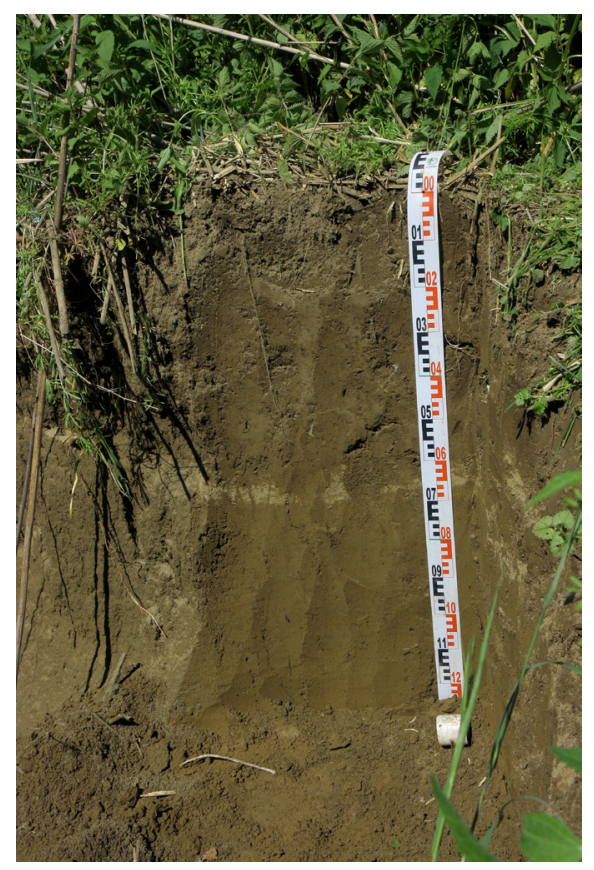

e

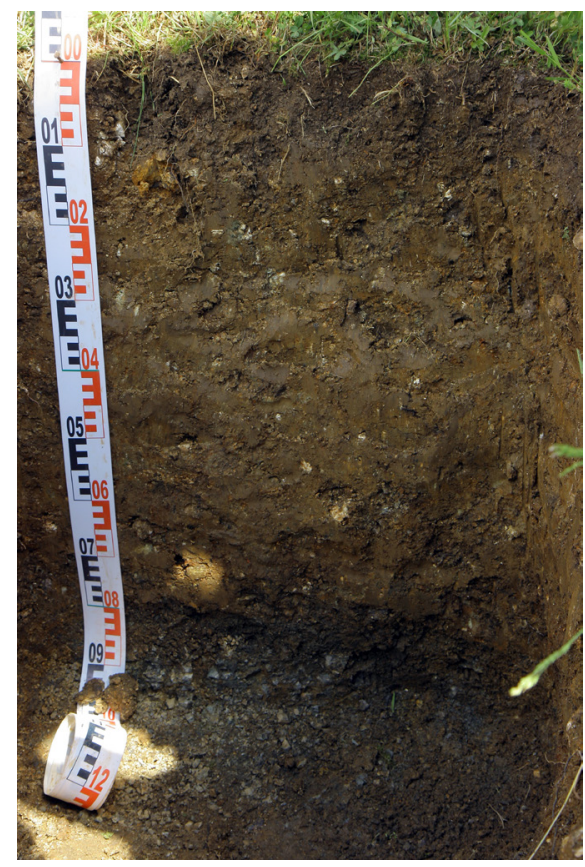

d

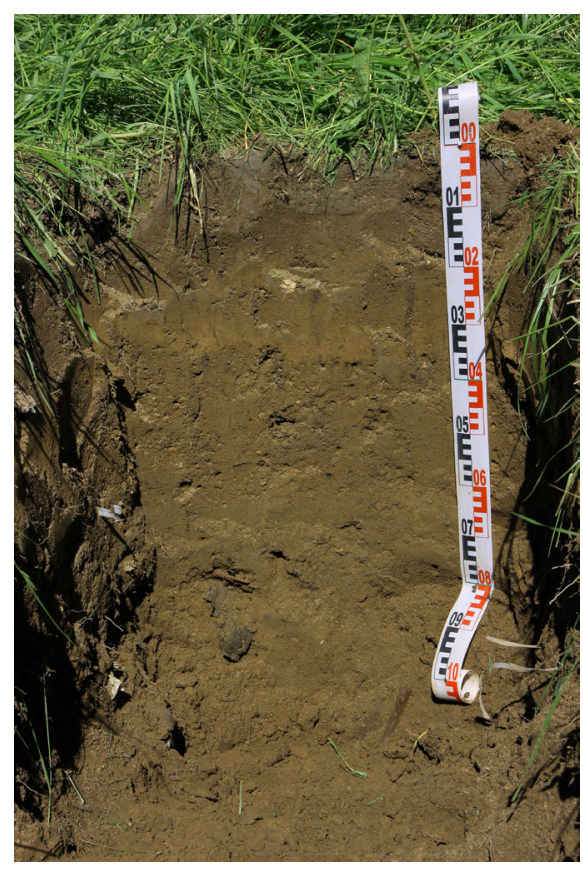

f 


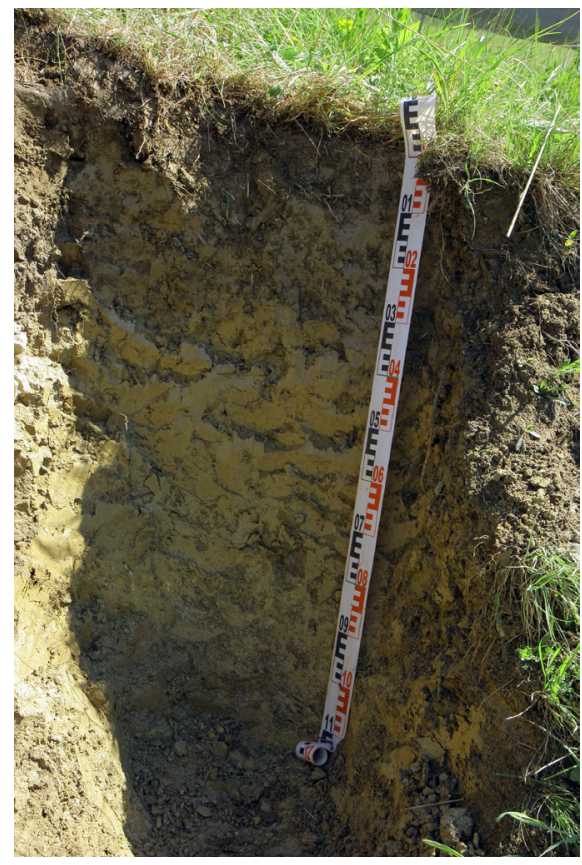

g

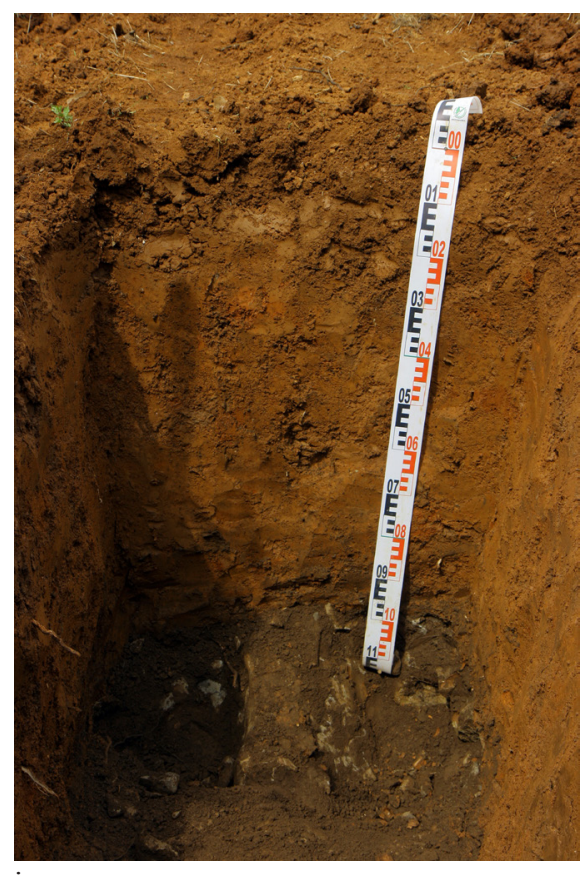

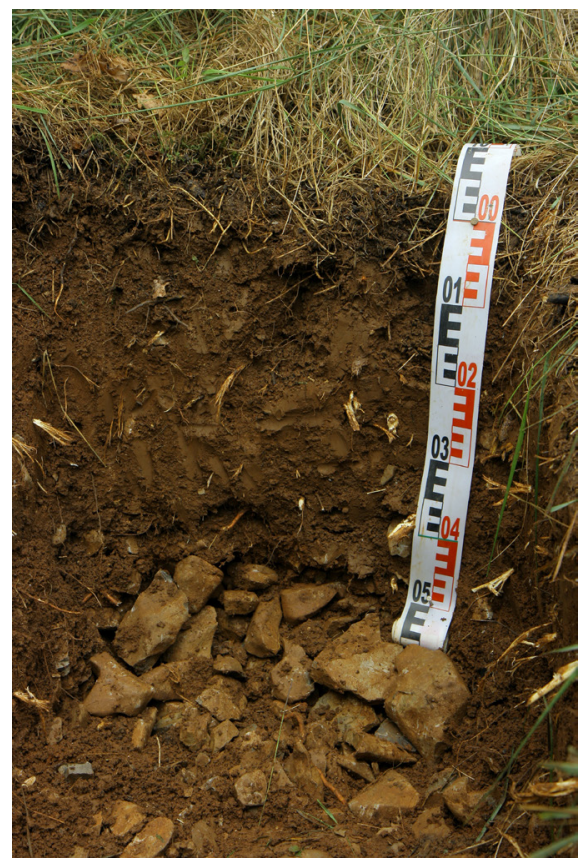

h

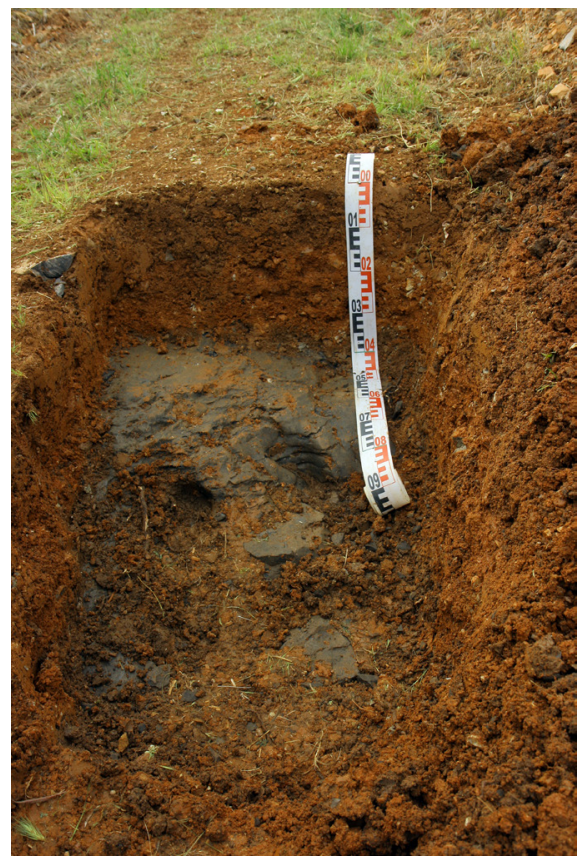

j 

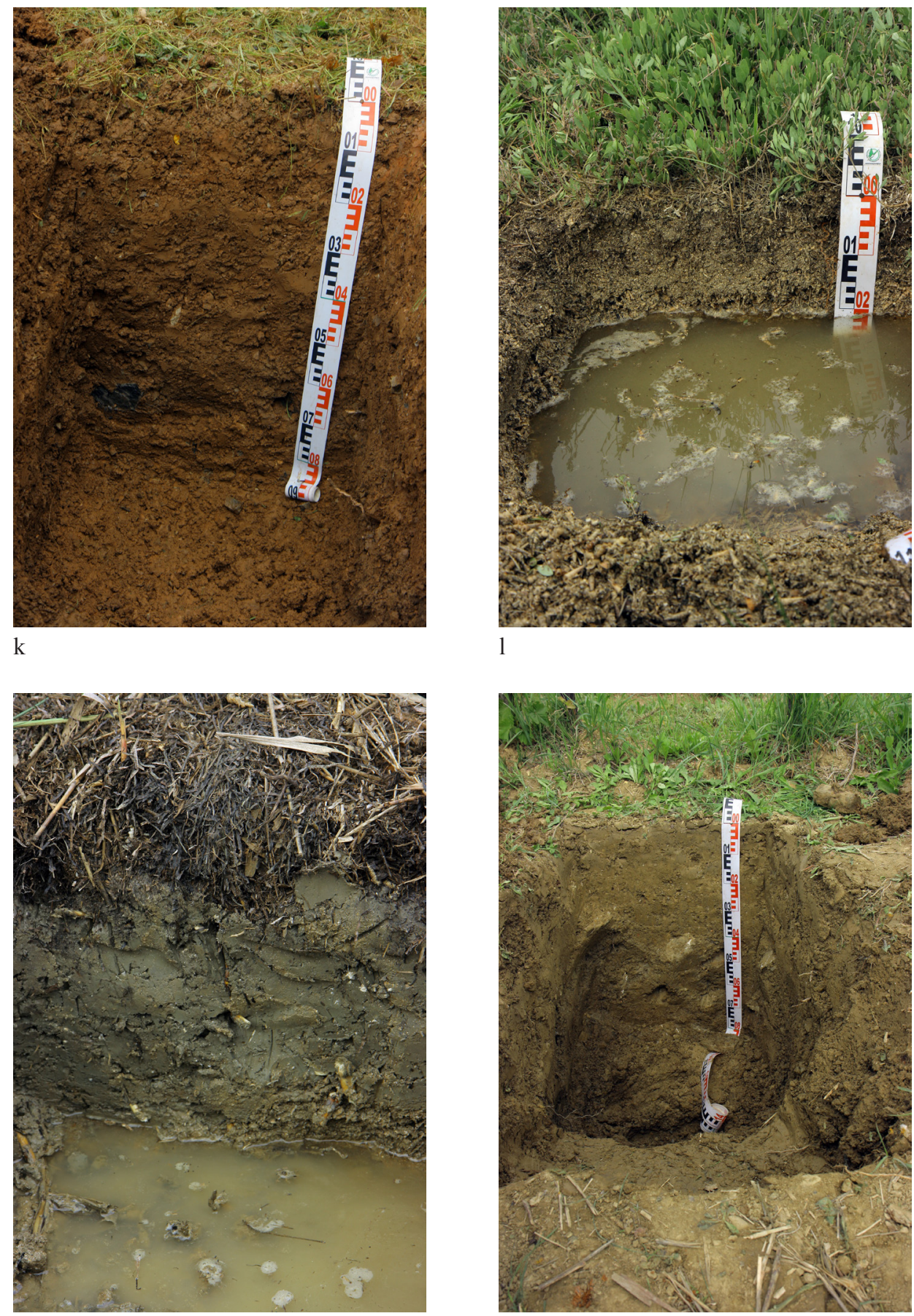

1

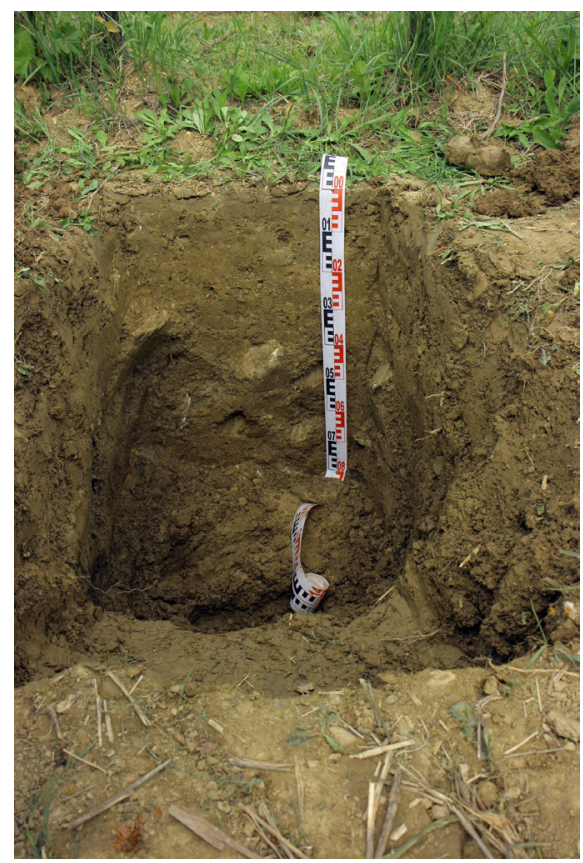




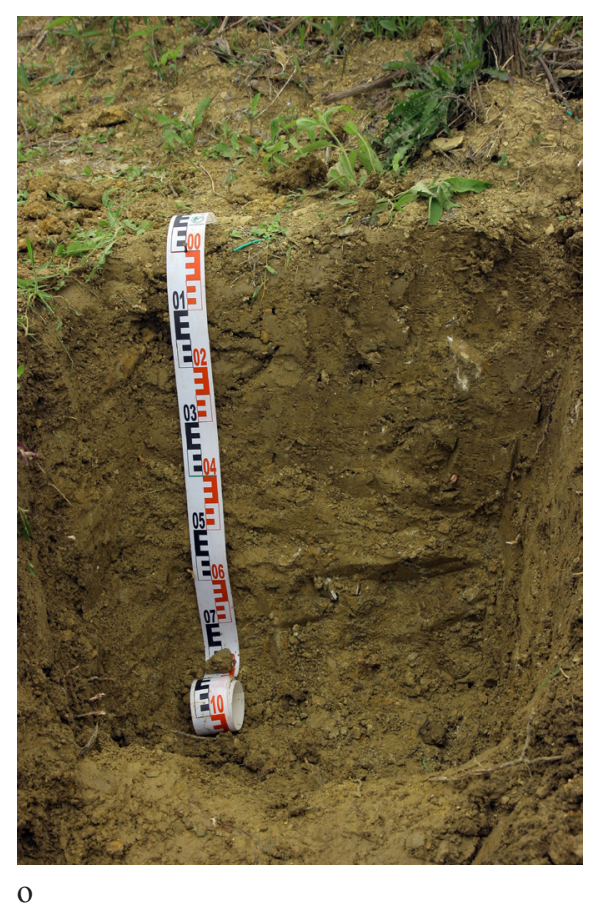

